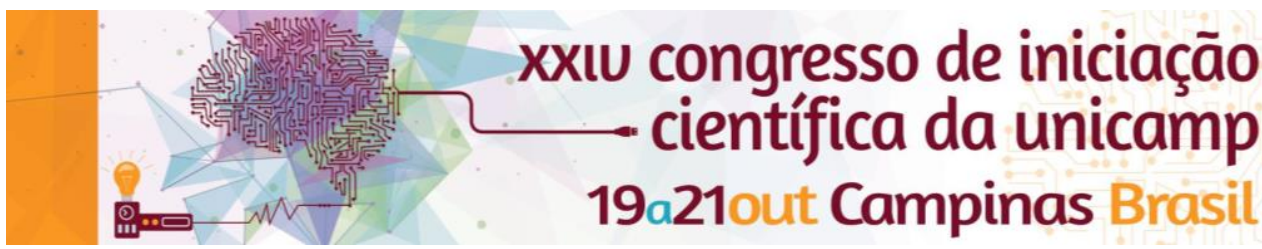

\title{
Reduction of maize post harvest losses in storage facilities.
}

Gabriel G. S. Vianna*, Rafael F. Novi, Oswaldo Lotti Neto, Bruno S. Cerqueira, Sara Medeiros.

\section{Abstract}

The determination of the breakage level in the processing steps will result in the loss mathematical model to be optimized.

\section{Key words:}

maize, post harvest loss, storage facility.

\section{Introduction}

Reduction of maize post harvest losses have been studied in many research institutions all around the world. In the food distribution chain, from harvest to consumption, reducing losses in the storage facility is the main objective of this project.

\section{Results and Discussion}

Maize samples were collected at the process steps of the post harvest storage facility, in Avaré, SP. The quality grade based on legislation of MAPA (2011) was determined, according to the Figure 1. The reduction of maize breakage content is the main objective of the project.

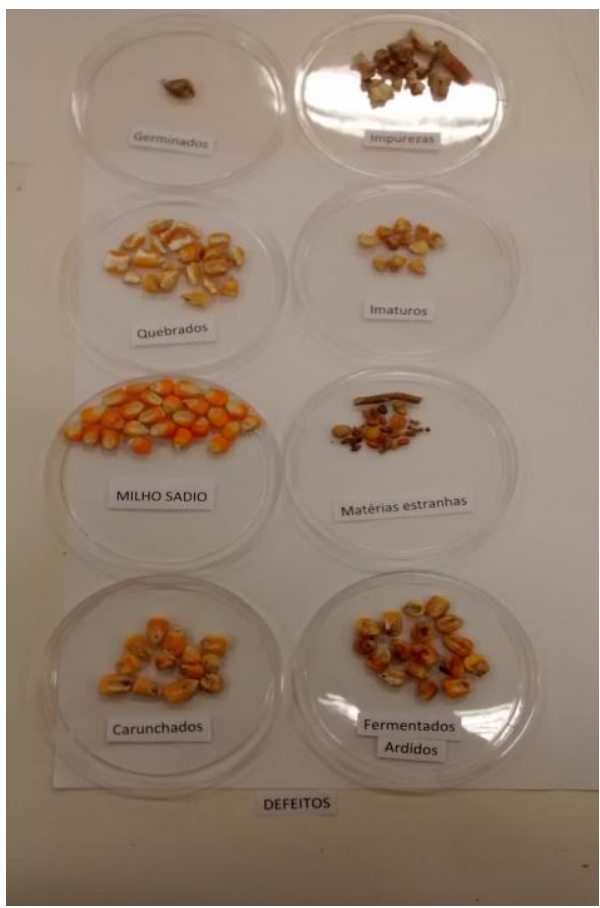

Figure 1. Integral maize grains and defects.

\section{Conclusions}

The cleaning and drying processes presented larger breakage level. A mathematical model would be developed, as function of mechanical and thermal stresses, and simulate breakage reduction due to the variable analysis.

\section{Acknowledgement}

Grateful to CEAGESP - Avaré for the maize samples.

Thankful to the FEAGRI's Postharvest Staff: R. Aguiar, A. Ono and R. Favoretto.

Campos, M. G; Avaliação da quebra técnica e qualidade do milho a granel, em função da temperatura de secagem e do tempo de armazenamento. Tese DOUTORADO.Viçosa, 2001

MAPA. IN60. Brasilia. 2011. 